\title{
VALIDAÇÃO LATERAL EM RELAÇÕES QUANTITATIVAS ENTRE ESTRUTURA E ATIVIDADE FARMACOLÓGICA, QSAR
}

\author{
Maria Luiza C. Montanari e Carlos A. Montanari* \\ Departamento de Química, Universidade Federal de Minas Gerais, CP 702, 31270-901 Belo Horizonte - MG \\ Anderson C. Gaudio \\ Departamento de Física, CCE, Universidade Federal do Espírito Santo, Vitória - ES
}

Recebido em 27/11/00; aceito em 6/7/01

\begin{abstract}
COMPARATIVE QSAR OF ANTIMICROBIAL HYDRAZIDES. The comparative QSAR is a tool for validating any statistical model that seems to be reasonable in describing an interaction between a bioactive new chemical entity, BIONCE, and the biological system. In order to deeper the understanding of the relationships and the meaning of parameters within the model it is necessary some kind of lateral validation. This validation can be accomplished by chemical procedures using physicochemical organic reactions and by means of biological systems. In this paper we review some of such comparisons and also present a lateral validation between the same set of antimicrobial hydrazides acting against Saccharomyces cerevisiae yeast and Escherichia coli bacterium cells. QSARs are presented to shed light in this important way of stating that the QSAR model is not the endpoint, but the beginning.
\end{abstract}

Keywords: QSAR; antimicrobial hydrazides; lateral validation.

\section{INTRODUÇÃO}

Uma análise da interação vida-química facilmente resulta em benefícios à saúde humana porque se está tentando estimar os efeitos tóxicos necessários e não-necessários de fármacos, pesticidas e substâncias químicas naturais e industriais em várias formas e partes da vida. A interação é um processo de duas mãos: enquanto as substâncias químicas afetam processos na vida, organismos vivos apresentam suas armas para atacar xenobióticos.

Uma maneira de compreender estas interações dá-se por relações entre a estrutura e a atividade, SAR. O principal aspecto inerente a esta observação vem da equação de Hammett

$\log k=\rho \sigma+$ constante

onde os valores de $\sigma$ são as constantes eletrônicas obtidas do (i) efeito do substituinte na ionização de ácidos benzóicos, (ii) da ionização de fenóis $\left(\sigma^{-}\right)$e (iii) da solvólise de $\mathrm{XC}_{6} \mathrm{H}_{4} \mathrm{CClMe}_{2}\left(\sigma^{+}\right) ; k$ é uma constante de equilíbrio ou de rapidez, enquanto $\rho$ é a medida da suscetibilidade da reação aos efeitos dos substituintes. Embora muitas dúvidas existam quanto ao funcionamento desta equação, a mesma trata de um dos conceitos de maior sucesso na elucidação dos mecanismos de reações.

Taft ampliou a equação de Hammett com a inclusão do parâmetro estéreo, $\mathrm{E}_{\mathrm{s}}$, que proporciona informações sobre a natureza do efeito do substituinte quando este estiver próximo do centro de reação. Hansch também ampliou a mesma equação quando introduziu o conceito de constantes lipofílicas em que sistemas biológicos são considerados.

Não obstante, a simples obtenção de uma relação quantitativa entre a estrutura química e a atividade farmacológica, QSAR, pode significar muito pouco no que diz respeito à sua validade e significado. A validação estatística do modelo constitui apenas a primeira

\footnotetext{
*e-mail: montana@dedalus.lcc.ufmg.br
}

aproximação do significado enquanto que a correlação por validação lateral em termos de várias outras QSARs pode introduzir maior robustez ao modelo antes que ele seja testado na prática. Neste contexto, por exemplo, a busca das relações que apresentem reações de substituição nucleofílica com valores de $\rho$ identificados em ordem crescente; a busca de todas as QSARs sobre bactérias; as reações em físico-química orgânica que contenham determinados coeficientes estéreos, $\mathrm{E}_{\mathrm{s}}$; a busca de todas as equações de QSAR em tópicos individuais como microssomos, cloroplastos, oxidorredutases, plantas, insetos, humanos; substituições eletrofílicas, nucleofílicas ou adições; reações que ocorram via radical livre, etc, podem constituir importantes bancos de dados capazes de consubstanciá-las de forma a propiciar uma validação lateral apropriada ${ }^{1-4}$.

Há, pelo menos, duas possibilidades de se realizar uma validação lateral: uma baseada em físico-química orgânica e outra em QSARs biológicas. A principal justificativa para isso pode ser encontrada no fato de que é muito pouco provável que uma QSAR apenas seja suficiente para imprimir um enorme significado nas interações vida-química - um sistema tão complexo que somente a mãe natureza é ainda capaz de entendê-lo em sua plenitude.

\section{VALIDAÇÃO DA QSAR ${ }^{1,5-10}$}

A validação da QSAR através da físico-química orgânica esbarra, inicialmente, nos parâmetros estatísticos. Embora os parâmetros sejam eventualmente satisfatórios ao entendimento de qualquer pessoa especializada em estatística, a questão importante a ser respondida é: o modelo foi obtido por correlação por chance, e caso contrário, o que ela significa? Parece óbvio, portanto, que a estatística sozinha não é capaz de responder a essa questão. Logo, uma validação lateral pode introduzir novas perspectivas em seu significado.

A Tabela 1 apresenta alguns exemplos ilustrativos da validação baseada em físico-química orgânica.

Embora as estruturas e as condições de reações bem como os substituintes sejam distintos para a equações A-C, Tabela 1, os valores de $\rho$ estão na média $2,25 \pm 0,25$. O significado deste resultado 
Tabela 1. Validações em físico-química orgânica

\begin{tabular}{|c|c|c|c|c|c|c|c|}
\hline No. & Tipo de reação & $\begin{array}{l}\text { Condições } \\
\text { experimentais }\end{array}$ & Equação & $\mathrm{n}$ & $\mathrm{r}^{2}$ & $\mathrm{~s}$ & Ref. \\
\hline A & Hidrólise alcalina de $\mathrm{XC}_{6} \mathrm{H}_{4} \mathrm{COOCMe}_{3}$ & $\begin{array}{l}\text { Etanol } \\
50 \% \text { a } 20{ }^{\circ} \mathrm{C}\end{array}$ & $\log \mathrm{k}=2,18 \sigma+0,62$ & 5 & 0,994 & 0,041 & 5 \\
\hline B & Hidrólise alcalina de $\mathrm{XC}_{6} \mathrm{H}_{4} \mathrm{COOC}_{2} \mathrm{H}_{5}$ & $\begin{array}{l}\text { Etanol } \\
87 \% \text {, a } 30^{\circ} \mathrm{C}\end{array}$ & $\log \mathrm{k}=2,51 \sigma-1,28$ & 18 & 0,986 & 0,105 & 5 \\
\hline $\mathrm{C}$ & Hidrólise alcalina de $\mathrm{XC}_{6} \mathrm{H}_{4} \mathrm{CN}$ & $\begin{array}{l}\text { Etanol } \\
60 \% \text { a } 82{ }^{\circ} \mathrm{C}\end{array}$ & $\log \mathrm{k}=2,13 \sigma-1,00$ & 5 & 0,962 & 0,184 & 5 \\
\hline $\mathrm{D}$ & Desacilação de $\mathrm{XC}_{6} \mathrm{H}_{4} \mathrm{COO}$-quimotripsina & $\mathrm{pH} 7,07,25^{\circ} \mathrm{C}$ & $\log \mathrm{k}=1,73 \sigma-2,07$ & 7 & 0,943 & 0,177 & 5 \\
\hline $\mathrm{E}$ & Idem & $\mathrm{pH} 8,5$ & $\log \mathrm{k}=1,73 \sigma-3,48$ & 11 & 0,922 & 0,275 & 5 \\
\hline $\mathrm{F}$ & Hidrólise alcalina de $\mathrm{XC}_{6} \mathrm{H}_{4} \mathrm{COOCH}_{3}$ & Solução aquosa & $\log \mathrm{k}=1,66 \sigma+1,92$ & 14 & 0,998 & 0,022 & 5 \\
\hline G & Inibição $\mathrm{I}_{50}$ de $E$. coli por $\mathrm{XC}_{6} \mathrm{H}_{4} \mathrm{~N}=\mathrm{C}=\mathrm{S}$ & - & $\log 1 / \mathrm{C}=2,27 \sigma+4,31$ & 9 & 0,927 & 0,161 & 5 \\
\hline $\mathrm{H}$ & $\mathrm{XC}_{6} \mathrm{H}_{4} \mathrm{~N}=\mathrm{C}=\mathrm{S}+\mathrm{C}_{2} \mathrm{H}_{5} \mathrm{OH}$ ® $\mathrm{XC}_{6} \mathrm{H}_{4} \mathrm{NHC}(=\mathrm{S}) \mathrm{OC}_{2} \mathrm{H}_{5}$ & - & $\log k=2,16 \sigma-4,80$ & 8 & 0,951 & 0,181 & 5 \\
\hline I & $\mathrm{XC}_{6} \mathrm{H}_{4} \mathrm{~N}=\mathrm{C}=\mathrm{S}+\mathrm{C}_{6} \mathrm{H}_{5} \mathrm{NH}_{2}{ }^{\circledR} \mathrm{XC}_{6} \mathrm{H}_{4} \mathrm{NHC}(=\mathrm{S}) \mathrm{NHC}_{6} \mathrm{H}_{5}$ & - & $\log k=2,14 \sigma-3,13$ & 4 & 0,988 & 0,060 & 5 \\
\hline
\end{tabular}

*Vide o texto para as explicações.

está, obviamente, aquém da físico-química orgânica clássica. Ele estabelece um ponto de referência para o estudo de hidrólise enzimática de ésteres. Por exemplo, na hidrólise do éster $\mathrm{XC}_{6} \mathrm{H}_{4} \mathrm{OCOCH}_{2} \mathrm{NHCOC}_{6} \mathrm{H}_{5}$ em tampão, $\rho=1,91$, mas $\rho$ para a hidrólise enzimática por tiol hidrolases no mesmo tampão é da ordem de $0,6^{5}$. A polarização da ligação éster pela enzima é o principal fator, e os efeitos polares dos substituintes contribuem muito pouco. Em outros casos, entretanto, a hidrólise enzimática valida hidrólises em sistemas não enzimáticos (ou vice-versa), Tabela 1 , equações D, E.

Nesses dois exemplos de hidrólises (do que pode ser considerado como ésteres de ácidos benzóicos) baseadas em diferentes séries de compostos, há uma boa concordância nos valores de $\rho$, embora sejam inferiores a aqueles mostrados nas equações A-C. Essas equações podem ser comparadas com a equação $\mathrm{F}$, Tabela 1 .

As validações laterais em QSARs baseadas em sistemas biológicos incluem mudanças estruturais complexas em termos de fatores (i) eletrônico, (ii) estéreo, (iii) lipofílico e (iv) topológico, que estão sendo analisadas em sistemas não-homogêneos.

Considere as seguintes equações ${ }^{5}$ :

$\log 1 / \mathrm{C}=3,55 \sigma-3,88 \sigma^{2}+1,62\left({ }^{3} \chi_{\mathrm{p}}^{\mathrm{v}}\right)-5,11$

$\left(\mathrm{n}=13, \mathrm{r}^{2}=0,762\right)$

$\log 1 / \mathrm{C}=0,92 \pi+2,08 \sigma-3,26$

$\left(\mathrm{n}=12, \mathrm{r}^{2}=0,794, \mathrm{~s}=0,314\right)$

para a atividade mutagênica de $\mathrm{XC}_{6} \mathrm{H}_{4} \mathrm{CH}_{2} \mathrm{~N}(\mathrm{Me}) \mathrm{N}=\mathrm{O}$ em Salmonela tifimurium TA 1535.

O parâmetro ${ }^{3} \chi_{p}^{v}$ é complexo. Ele é obtido da teoria de grafos cujo significado não é claro. Entretanto, é lícito considerar que seja colinear com a constante lipofílica, $\pi$. Não obstante, a questão importante a ser respondida é: qual das equações deve ser escolhida para futuros trabalhos? Os coeficientes de correlação são similares; a equação (2) tem três variáveis independentes enquanto que a (3) tem apenas dois, mas tem um objeto (composto) a menos. Questões como estas podem ser respondidas apenas com o estudo ampliado da validação lateral do modelo QSAR.

O estudo das interações hidrofóbicas em mutagêneses ilustra essa questão. O coeficiente angular (h) em $\log \mathrm{P}$ de oito QSARs diferentes para uma variedade de compostos atuando em uma variedade de sistemas biológicos em teste pode ser encontrado na Tabela (2)

Os valores dos coeficientes angulares (h) estão na magnitude de 1 em termos do parâmetro lipofílico. Por isso, parece razoável assu-
Tabela 2. Coeficientes angulares (h) em $\pi$ ou log P para diferentes tipos de compostos agindo em testes de mutagênese bacteriana

\begin{tabular}{lll}
\hline Tipo do composto & Teste & $\mathrm{h}$ \\
\hline Composto nitro-aromáticos e heteroaromáticos & TA98 & 0,65 \\
Composto nitro-aromáticos e heteroaromáticos & TA100 & 1,10 \\
Aminas aromáticas e heteroaromáticas & TA98 & 1,08 \\
Aminas aromáticas e heteroaromáticas & TA100 & 0,92 \\
Compostos nitro-aromáticos & E. coli & 1,07 \\
$\mathrm{XC}_{6} \mathrm{H}_{4} \mathrm{~N}=\mathrm{NN}(\mathrm{R}) \mathrm{CH}_{3}$ & TA92 & 0,95 \\
$\mathrm{XC}_{6} \mathrm{H}_{4} \mathrm{CH}_{2} \mathrm{~N}(\mathrm{Me}) \mathrm{N}=\mathrm{O}$ & TA1535 & 0,92 \\
Quinolinas & TA100 & 1,14 \\
\hline
\end{tabular}

mir que a equação (3) deva ser escolhida para futuros estudos, pelo menos até que o parâmetro ${ }^{3} \chi_{\mathrm{p}}^{\mathrm{v}}$ seja adequadamente validado!

Uma maneira diferente de correlação lateral pode ser encontrada por comparação de sistemas biológicos diferentes interagindo com a mesma série de compostos químicos. As duas equações abaixo servem como exemplo para ilustrar a validação ${ }^{5}$.

$\log 1 / \mathrm{C}=0,92 \log \mathrm{P}+0,53$

$\left(\mathrm{n}=12, \mathrm{r}^{2}=0,996, \mathrm{~s}=0,101\right)$

para a inibição de $50 \%$ do crescimento de leveduras e,

$\log 1 / \mathrm{C}=0,91 \log \mathrm{P}+0,19$

$\left(\mathrm{n}=12, \mathrm{r}^{2}=0,986, \mathrm{~s}=0,162\right)$

para a concentração inibitória mínima (MIC) na condução nervosa de baratas.

Os coeficientes angulares das duas equações acima são muito parecidos, sugerindo que compostos lipofílicos perturbam a membrana de maneira similar.

A validação lateral também pode ser realizada em sistemas em que fatores eletrônicos e/ou estéreos estejam envolvidos. As equações G-I da Tabela 1 mostram os resultados.

A concordância entre os valores de $\rho$ sugere que a inibição do crescimento de $E$. coli por isotiocianatos acontece em reações com fragmentos nucleofílicos dentro da célula. A falta de um termo hidrófobo indica que não há uma barreira lipofílica entre os isotiocianatos e os nucleófilos necessários para a inibição. Compare, ainda, estas equações com aquelas A-C da mesma Tabela 1. 
Um exemplo que evidencia a importância de fatores eletrônicos e estéreos pode ser visto a seguir 5 .

$\log 1 / \mathrm{C}=-3,70 F+0,89 E_{s}+5,78$

( $\left.\mathrm{n}=17, \mathrm{r}^{2}=0,835, \mathrm{~s}=0,368\right)$

para a concentração inibitória mínima, MIC, de Mycobacterium tuberculosis por<smiles>[X]c1cc(C(N)=O)ccn1</smiles>

$\mathrm{e}$,

$\log k=-3,02 F+0,61 E_{s}+0,11$

$\left(\mathrm{n}=17, \mathrm{r}^{2}=0,870, \mathrm{~s}=0,275\right)$

para a rapidez relativa na alquilação de 2 -X-piridinas por iodeto de metila em metanol.

A concordância entre os termos indutivo (campo) e estéreo é razoável do ponto de vista que um sistema homogêneo está sendo comparado a um heterogêneo.

O significado de um parâmetro padrão relativo ao grau de lipofilia de substâncias químicas pode ser ilustrado de maneira geral. Uma QSAR clássica mostrou que os valores ótimos de log $\mathrm{P}$ para a penetração de uma série de ácidos fenilborânicos no cérebro de camundongos era 2,3. Posteriormente, foi mostrado que uma grande variedade de substâncias químicas atuando como depressoras do sistema nervoso central, CNS, também possuía um log P próximo de dois. Dessa forma, o planejamento de novas substâncias com ação em CNS deve buscar o coeficiente de partição igual ou similar a dois, desde que outros fatores sejam similares ou iguais. Por outro lado, é bom enfatizar que esse resultado também ajuda na manutenção de outras substâncias fora do CNS.

Neste trabalho a mesma série de hidrazidas antimicrobianas foi testada, através da microcalorimetria biológica, frente à Saccharomyces cerevisiae e Escherichia coli. A validação das QSARs obtidas foi estabelecida.

\section{MATERIAIS E MÉTODOS}

A síntese das hidrazidas $\left(\mathrm{X}-\mathrm{C}_{6} \mathrm{H}_{4}-\mathrm{C}(\mathrm{O}) \mathrm{NHNHC}(\mathrm{O}) \mathrm{C}_{6} \mathrm{H}_{5}, \mathrm{X}=\right.$ $\mathrm{H}, \mathrm{Br}, \mathrm{NO}_{2}, \mathrm{OMe}, \mathrm{Me}, \mathrm{C}_{6} \mathrm{H}_{5}$, Pent, $t$-Bu) já está descrita ${ }^{11}$. Os estudos da atividade farmacológica ${ }^{12}$ bem como do coeficiente de partição ${ }^{13}$ também já foram descritos previamente.

Os cálculos dos parâmetros físico-químicos e topológicos para as oito hidrazidas em estudo foram realizados através do programa TSAR $^{14}$, operando em uma estação de trabalho SiliconGraphics O2. As QSARs foram obtidas através do mesmo programa. As estruturas tridimensionais das hidrazidas em estudo foram obtidas por modelagem molecular através do programa Sybyl v.6.5.3 ${ }^{15}$. As cargas foram geradas através do modelo de Gasteiger-Huckel, no mesmo programa.

\section{RESULTADOS E DISCUSSÃO}

A equação 8 mostra a QSAR para a dependência da potência de acilidrazinas frente à $S$. cerevisiae, através do descritor lipofílico $\pi \mathrm{e}, \mathrm{a}$ Tabela 3, os parâmetros originais. Os parâmetros estatísticos são significativos para a atividade das acilidrazinas, mas a validação cruzada (capacidade de predição) não é boa, já que apenas cerca de $38 \%$ da variância total está sendo predita pelo referido descritor. Para apenas um único descritor esse percentual pode ser considerado pequeno.

$\log 1 / \mathrm{C}_{(50) \mathrm{S} . \mathrm{c}}=-0,210( \pm 0,13) \pi+3,745( \pm 0,18)$

$\left(\mathrm{n}=8 ; \mathrm{r}^{2}=0,728 ; \mathrm{s}=0,153 ; \mathrm{F}=16,073 ; \mathrm{r}_{\mathrm{cv}}^{2}=0,382\right)$

$\mathrm{O}$ resultado indicado na equação 8 mostra que, quanto maior a

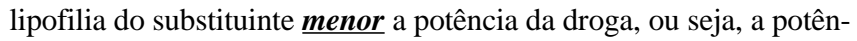
cia aumenta com a hidrofilia da molécula. Esse resultado é obtido por uma análise do coeficiente angular da reta, que é negativo. $\mathrm{O}$ efeito hidrófobo é detrimental para a ação biológica, o que não é comum $^{16,17}$. É bem sabido que o aumento da concentração na fase lipóide provoca um aumento da potência da droga, mas não o contrário, ou seja, o aumento do caráter hidrofílico da droga é que está provocando o aumento da potência.

O coeficiente angular da equação 8 não está próximo da unidade, o que sugere uma relação não homo-energética da potência com

Tabela 3. Parâmetros biológicos e lipofílicos das hidrazidas em estudo

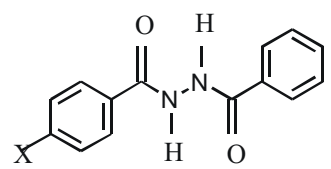

\begin{tabular}{|c|c|c|c|c|c|c|c|c|c|c|}
\hline X & $\pi^{1}$ & $\sigma_{\mathrm{P}}^{1}$ & $M R^{I}$ & $\begin{array}{c}\log D_{50}^{2} \\
(\mathrm{Ec}) \\
\left(\mu \mathrm{mol} . \mathrm{L}^{-1}\right)\end{array}$ & $\begin{array}{c}\log D_{50}^{2} \\
(\mathrm{Sc}) \\
\left(\mu \mathrm{mol} . \mathrm{L}^{-1}\right)\end{array}$ & $\begin{array}{c}\log P_{T A}^{3} \\
(\mathrm{Ec})\end{array}$ & $\begin{array}{c}\log P_{T A}{ }^{3} \\
(\mathrm{Sc})\end{array}$ & $\begin{array}{l}\pi_{T A}{ }^{4} \\
(\mathrm{Sc})\end{array}$ & $\begin{array}{l}\pi_{T A}{ }^{4} \\
(\mathrm{Ec})\end{array}$ & $\log \mathrm{k}_{\mathrm{w}} 5$ \\
\hline $\mathrm{Br}$ & 0,86 & 0,23 & 8,88 & 2,73 & 2,47 & $-0,879$ & $-0,693$ & 0,201 & 0,215 & 2,754 \\
\hline $\mathrm{CH}_{3}$ & 0,56 & $-0,17$ & 5,65 & 2,54 & 2,54 & $-0,956$ & $-0,782$ & 0,112 & 0,138 & 2,516 \\
\hline $\mathrm{C}\left(\stackrel{\mathrm{C}}{\mathrm{C}} \mathrm{H}_{3}\right)_{3}$ & 1,98 & $-0,20$ & 19,62 & 3,21 & 2,75 & $-0,799$ & $-0,516$ & 0,378 & 0.295 & 2,726 \\
\hline $\mathrm{C}_{6} \mathrm{H}_{5}$ & 1,96 & $-0,01$ & 25,36 & 3,23 & 2,90 & $-0,787$ & $-0,532$ & 0,362 & 0,307 & 2,871 \\
\hline $\mathrm{H}^{\circ}$ & 0,00 & 0,00 & 1,03 & 2,28 & 2,14 & $-1,094$ & $-0,894$ & 0,000 & 0,000 & 2,052 \\
\hline $\mathrm{NO}_{2}$ & $-0,28$ & 0,78 & 7,36 & 2,41 & 2,22 & $-1,140$ & $-0,944$ & $-0,005$ & $-0,046$ & 2,250 \\
\hline $\mathrm{OCH}_{3}$ & $-0,02$ & $-0,27$ & 7,87 & 2,60 & 2,33 & $-1,001$ & $-0,833$ & 0,061 & 0,093 & 2,344 \\
\hline $\mathrm{C}_{5} \mathrm{H}_{11}^{3}$ & 2,67 & $-0,16$ & 24,26 & 3,05 & 2,62 & $-0,652$ & $-0,439$ & 0,455 & 0,442 & 2,936 \\
\hline
\end{tabular}

${ }^{1}$ Valores obtidos da referência Hansch, C.; Leo, A.; Hoekman, D.; In Exploring QSAR. Hydrophobic, Electronic and Steric Constants; ACS, Washington, 1995.

${ }^{2}$ Concentração necessária para inibir $50 \%$ do metabolismo das células de E. coli e S. cerevisiae, respectivamente.

${ }^{3}$ Valores relativos do coeficiente de partição obtido através da difusão modificada de Taylor-Aris, em sistemas celulares constituídos de meios de cultura apropriados para $E$. coli e $S$. cerevisiae.

${ }^{4}$ Constante lipofílica de Taylor-Aris: $\pi_{\mathrm{TA}}=\log \mathrm{P}_{\mathrm{X}}-\log \mathrm{P}_{\mathrm{H}}$.

${ }^{5}$ Valores absolutos do coeficiente cromatográfico de partição, determinados via RP-HPLC. 
o coeficiente lipofílico. É bem provável, como anteriormente ressaltado, que a descrição da potência necessite de outro mecanismo que não puramente o de partição.

A inclusão de termos eletrônicos e estéreos não melhorou a correlação, mas o uso da refratividade molar, $M R$, demonstra que há uma melhora do modelo. Veja discussão abaixo para o uso de $M R$ como melhor descritor físico-químico para a atividade biológica das acilidrazinas. Observa-se, entretanto, que não se trata de um termo aditivo, mas sim de um termo que descreve sozinho a atividade farmacológica.

Como mencionado acima, é pouco comum que o uso da lipofilia não seja discernível ou pelo menos pouco discernível nos estudos de QSAR em sistemas celulares. O exemplo mais notável é aquele mostrado pelas sulfas, que descrevem a potência através de um coeficiente negativo para a partição ${ }^{16,18,19}$. Seydel e colaboradores, no entanto, encontraram outro exemplo no caso de hidrazidas do ácido nicotínico atuando frente a $M$. tuberculosis. Seydel e colaboradores usaram valores de $R_{\mathrm{m}}$ para a obtenção das propriedades lipofílicas e Hansch e Leo ${ }^{20}$ usaram $\log P$, mas nenhum dos parâmetros descreveu os dados adequadamente. As duas proposições de Hansch e Leo que parecem ser adequadas ao presente estudo são: o transporte ativo por um sistema com propriedades hidrofílicas poderia transportar a droga através da membrana lipídica e/ou o receptor poderia estar localizado próximo da superfície de modo que, como consequiência, a droga poderia alcançá-lo através de um canal polar.

A constante lipofílica, $\pi$, representa apenas a contribuição fragmental do substituinte. Na descrição da dependência linear da potência de acilidrazinas frente à $S$. cerevisiae, o coeficiente para log $P$ está próximo da unidade, o que reflete uma interação homoenergética. Veja a equação 13. Então, é bem provável também que esse outro mecanismo represente a natureza global da molécula em termos de sua capacidade de particionar, ou seja, o balanço hidrataçãodesidratação envolve toda a molécula e não apenas uma subunidade lipofílica. O coeficiente angular de $\log P$ versus $\pi$ (veja a equação 14) é relativamente próximo, embora menor, daquele mostrado na equação 8 , mas é, certamente, muito distante da unidade. Isso demonstra que o próprio $\log P$ não está sendo definido apenas pela constante lipofílica do substituinte e, portanto, o fenômeno de transporte não está sendo governado apenas por uma subunidade molecular, mas sim pela molécula global. É provável ainda que $\pi$ esteja descrevendo apenas a "cavidade" eletrofílica do sítio de interação que reconhece e engalfinha essa subunidade estrutural. $\mathrm{O}$ seu intercepto (equação 8) também é bem elevado e demonstra que no início, ou seja, quando $\pi$ é zero, a resposta biológica ainda é muito sensível. Esse resultado também confirma a expectativa de que as substâncias mais potentes estejam alinhadas com as substâncias mais hidrofílicas da série em estudo.

A lipofilia é considerada através das mudanças na energia livre da dessolvatação de um composto no seu movimento da fase aquosa para a biofase. A água de solvatação é mantida junto ao soluto ${ }^{21,22} \mathrm{de}$ diferentes maneiras: estruturada ao redor do fragmento não polar, por ligações de hidrogênio e por interações dipolares. Nesse contexto, $\pi$ poderia representar apenas a identificação da cavidade lipofílica (hidrofílica no presente estudo), ao nível do receptor.

\section{Descritores Físicos da Estrutura Tridimensional (3D)}

A importância da estereosseletividade na ação de um fármaco é bem conhecida. Há muitos exemplos que mostram a atividade dependente da sua configuração e geometria. Um dos exemplos é a diferença estabelecida entre isômeros ópticos, devido às suas capacidades de interagir seletivamente com um sistema biológico. Foram os físicoquímicos orgânicos que definiram inúmeros parâmetros estéreos para a descrição dos efeitos estéreos de substituintes em centros de reações de moléculas orgânicas. O mesmo tipo de efeito estéreo pode ser estabelecido e observado em estudos da variação das propriedades físicas e químicas, assim como a reatividade química, com a estrutura, quando um fármaco está envolvido em um sistema biológico.

Os descritores estéreos são classificados entre: (a) índices topológicos baseados na caracterização da estrutura química pela teoria de grafos, (b) descritores geométricos que resultam da visão de moléculas orgânicas em três dimensões, (c) descritores químicos que são derivados da influência estérea sobre reações padrões, (d) descritores físicos que resultam quando moléculas orgânicas são consideradas como objetos em três dimensões e seus tamanhos são determinados por propriedades físicas e (e) descritores diferenciais que resultam quando uma molécula orgânica é considerada como um objeto em três dimensões e que varia como resultado das diferenças com uma estrutura referência, através do método da sobreposição. Não é o objetivo deste artigo a discussão de cada um desses métodos, para o que se recomenda a referência ${ }^{23}$. Ao contrário, apenas alguns descritores físicos serão estudados e, em particular, o de refratividade molar, $M R$.

Charton $^{24}$ mostrou que os volumes de van der Waals, $V_{\mathrm{w}}$, são, em geral, muito correlacionados com a $M R$, que também pode representar fatores de polarizabilidade ao invés de fatores estéreos. Esta observação não é, entretanto, surpreendente, já que a $M R$ está relacionada com o volume molar pela equação de Lorenz-Lorentz $(M R=$ $\left.\left(n^{2}-1 / n^{2}+2\right) \cdot M W / d\right)$. O intervalo de variação do índice de refração é pequeno e, conseqüentemente, $M R$ é, em essência, o volume molar ajustado que contém uma contribuição eletrônica. Na realidade, a polarização de uma substância é dada pela equação 9, pois quando a relação de Maxwell $n^{2}=\varepsilon$ é estabelecida, a refratividade molar iguala-se à polarização molar.

$P_{M}=(\varepsilon-1) /(\varepsilon-2) \cdot M W / d$

onde $\varepsilon$ representa a constante dielétrica.

Além disso, Dunn ${ }^{25}$ mostrou que a polarizabilidade de uma molécula está relacionada com a polarização molar e a refratividade molar $^{26}$, enquanto que Cammarata ${ }^{27}$ mostrou a dependência com o parâmetro lipofílico $\log P^{28}$. Como consequiência natural, $M R$ também pode ser dependente de $\pi$, já que ambos dependem do volume molar. Apesar disso, dependendo de uma escolha apropriada dos substituintes, $M R$ pode ser ortogonal a $\pi$ e, nesse caso, suas importâncias relativas podem ser estabelecidas.

Parece evidente que o papel de $M R$ para um ligante pode ser ambivalente. Ele pode representar forças dispersivas que ajudam a interação do ligante ao receptor ${ }^{29}$. Nesses casos esperar-se-ia um coeficiente positivo para $M R$. Alternativamente, uma vez que $M R$ é, até um certo grau, uma medida de volume, ele pode medir a capacidade de o ligante distorcer a conformação do receptor para assim evitar a interação com o substrato. Como a mudança conformacional é detrimental, poder-se-ia esperar um sinal negativo para esse termo. Os coeficientes angulares negativos refletem, portanto, o impedimento estereoquímico.

Os dados biológicos quantitativos descritos acima podem ser avaliados em termos de $M R$. A equação 10 mostra os resultados obtidos para a dependência linear de $M R$ frente à $S$. cerevisiae.

$\log 1 / \mathrm{C}_{(50) \text { s.c }}=-0,273( \pm 0,11)(0,1) \mathrm{MR}+3,883( \pm 0,17)$

$\left(\mathrm{n}=8 ; \mathrm{r}^{2}=0,857 ; \mathrm{s}=0,111 ; \mathrm{F}=36,66 ; \mathrm{r}^{2}{ }_{\mathrm{cv}}=0,712\right)$

A primeira hipótese que pode ser estabelecida a partir da equação acima é que as perturbações causadas pelos substituintes estão 
correlacionadas com $M R$, sendo relativas às interações com resíduos polares do sítio receptor ou seu tamanho. O coeficiente angular negativo é uma indicação de que esse último é o fenômeno que está operando.

Como $M R$ também é uma medida do volume do substituinte, ele pode ser responsável por mudanças conformacionais no receptor. $M R$ é negativo e não é substituído por $E_{\mathrm{s}}$ (um descritor químico) já que há uma perda da qualidade do modelo. Portanto, é bem provável a existência de uma contribuição estereoquímica dos substituintes na posição-para da benzoilidrazina.

A equação 10 mostra que $86 \%$ da potência pode ser explicada pela refratividade molar. Uma comparação entre as equações 8 e 10 mostra que a melhor correlação é encontrada através do uso de $M R$ como descritor físico-químico e não $\pi$. Entretanto, uma análise mais detalhada evidencia um elevado grau de similaridade entre ambas $\left(\mathrm{r}^{2}\right.$ = 0,876). A inclusão dos descritores $\pi$ e $M R$ no mesmo modelo não produz qualquer correlação significativa em $\pi$ e um efeito aditivo entre ambos não está sendo estabelecido. Não obstante, essa aditividade não seria esclarecedora devido à elevada colinearidade entre ambos os descritores. Os coeficientes angular e intercepto são muito parecidos em ambos os modelos. Isso estabelece um grau de dificuldade na distinção entre ambos, apesar de, estatisticamente, o modelo representado pela equação 10 ser melhor. A capacidade de predição da equação 10 é muito superior àquela estabelecida pela equação 8 , o que leva a optar pela equação 10 .

Apesar de $E_{\mathrm{s}}$ não ser importante para a descrição da potência das acilidrazinas em estudo, outros parâmetros estereoquímicos, tais como $E_{\mathrm{s}}^{\mathrm{c}}$, STERIMOL, volume molar, podem ser usados no lugar de $M R^{4}$.

Uma tentativa de correlacionar $M R$ com o parâmetro STERIMOL, $L$, resultou na equação 11 .

$(0,1) \mathrm{MR}=0,515( \pm 0,21) \mathrm{L}-0,906( \pm 0,94)$

$\left(\mathrm{n}=8, \mathrm{r}^{2}=0,857, \mathrm{~s}=0,377, \mathrm{~F}=35,96, \mathrm{r}_{\mathrm{cv}}^{2}=0,769\right)$

Hansch e $\mathrm{Leo}^{30}$ mostraram que $M R$ de 101 substituintes diferentes também são correlacionados aos parâmetros esterimol $B 1, B 5$ e $L$. Entretanto, como se pode observar pela equação 11 apenas $L$ descreve $M R$. Os demais parâmetros não são significativos. É interessante observar que o coeficiente angular de $L$ na equação de HanschLeo, 0,4, é próximo daquele mostrado na equação 11 , ou seja 0,5 .

O parâmetro esterimol $L$ também descreve a potência das acilidrazinas em estudo, mas o coeficiente de correlação é 0,6 , enquanto que o coeficiente angular é $-0,127$, relativamente próximo daquele mostrado na equação 8 . Como $L$ representa o comprimento do substituinte ao longo do eixo da ligação a partir do carbono-4 do grupo fenila da acilidrazina, é provável que a cavidade do receptor não seja alongada, já que o n-pentila, por exemplo, o substituinte mais longo, apresenta uma das menores potências relativas, enquan- to que os menores grupos $\mathrm{H}$ e Me, são os mais potentes. $\Pi$ também é descrito por $L\left(r^{2}=0,674\right)$ e o coeficiente angular é 0,547 . Apesar disso, a potência das acilidrazinas continua sendo mais bem descrita por $M R$, sozinho. Mas parece óbvio que $M R$ contém uma dependência estérea intrínseca e isso está sendo refletido na dependência da potência sobre o descritor geométrico $L$, elucidando uma característica extremamente importante sobre a natureza do receptor, assim mapeado.

Para uma série homóloga, $\log P$ e o tamanho do substituinte seriam perfeitamente colineares. Portanto, não é, em geral, muito fácil o planejamento de uma série congenérica em que ambos não sejam parcialmente colineares. No presente estudo, $\log P_{\mathrm{TA}},{ }^{13}$ é bem correlacionado com $M R\left(\mathrm{r}^{2}=0,821\right)$ e também é relacionado com $L$ $\left(\mathrm{r}^{2}=0,635\right)$. Entretanto, o que é surpreendente é o fato de que o coeficiente angular de $L, 0,094$, estabelece que $\log P_{\text {TA }}$ é muito pouco susceptível a $L$. O coeficiente de $M R$ também é muito pouco significativo $(0,192)$ e ambos são relativamente semelhantes, mas ambos não têm qualquer significado quando considerados aditivamente pela equação de Hansch/Fujita ${ }^{4}$. Uma possibilidade de descrever o tamanho dos substituintes dá-se através do uso da massa molar. Mas uma tentativa de correlacionar $\log P_{\mathrm{TA}} \operatorname{com} M W$ não levou a qualquer resultado significativo. $\mathrm{O}$ mesmo aconteceu para $\log 1 / \mathrm{D}_{50}(\mathrm{Sc})$ versus $M W$.

O volume dos substituintes pode ser usado no lugar de $M R$. Estes volumes calculados por dois métodos diferentes são aqueles representados por $\mathrm{MG}-\mathrm{Vol}^{4,31}$ e SA-Vol ${ }^{4,32}$ e podem ser encontrados, juntamente com alguns outros, na Tabela 4.

$M R$ é colinear com MG-Vol, $\mathrm{r}^{2}=0,974$, e $L$ também é, $\mathrm{r}^{2}=0,826$. Então, embora as correlações acima sejam relativamente ineficazes está claro que tanto $M R$ como $L$ apresentam uma constituição de volume molar intrínseca.

\section{Efeito Eletrônico}

A equação 12 mostra os resultados da análise estatística para as potências frente à $S$. cerevisiae estabelecidas, quando o parâmetro eletrônico de Hammett $\rho_{\mathrm{p}}$ foi usado como descritor físico-químico. Como se pode observar, não há uma correlação estabelecida entre $\sigma_{\mathrm{p}}$ e $\log 1 / \mathrm{C}_{50}$. A capacidade de predição do modelo não tem qualquer significado.

$\log 1 / \mathrm{C}_{(50) \mathrm{s.c}}=0,245( \pm 0,75) \sigma_{\mathrm{p}}+3,536( \pm 0,24)$

$\left(\mathrm{n}=8 ; \mathrm{r}^{2}=0,095 ; \mathrm{s}=0,279 ; \mathrm{F}=0,632 ; \mathrm{r}_{\mathrm{cv}}=-0,440\right)$

A seleção do intervalo de variação de $\sigma_{p}$ é: $-0,27 \leq \sigma_{p} \leq 0,78$. Isso mostra que apesar do intervalo relativamente bom, esse descritor eletrônico não foi necessário para descrever a atividade farmacológica em estudo. O valor de $\rho$ da QSAR mostrada na equação 12 é positi-

Tabela 4. Alguns descritores físico-químicos em uso

\begin{tabular}{ccccccccc}
\hline $\begin{array}{c}\text { Descritor/ } \\
\text { Substituinte }\end{array}$ & $\mathrm{Br}$ & $\mathrm{NO}_{2}$ & $\mathrm{H}$ & $\mathrm{Me}$ & $\mathrm{OMe}$ & $t-\mathrm{Bu}$ & $\mathrm{C}_{5} \mathrm{H}_{11}$ & $\mathrm{C}_{6} \mathrm{H}_{5}$ \\
\hline $\mathrm{E}_{\mathrm{s}}$ & $-1,16$ & $-1,765$ & 0 & $-1,24$ & $-0,55$ & $-2,78$ & $-1,64$ & $-1,66$ \\
$F$ & 0,44 & 0,67 & 0 & -0.02 & 0.26 & -0.07 & -0.06 & 0.08 \\
$r$ & -0.17 & 0.16 & 0 & $-0,13$ & $-0,51$ & $-0,13$ & $-0,09$ & $-0,08$ \\
$L$ & 3,82 & 3,44 & 2,06 & 2,83 & 3,98 & 4,11 & 6,97 & 6,28 \\
$B 1$ & 1,95 & 1,70 & 1,00 & 1,52 & 1,35 & 2,60 & 1,52 & 1,71 \\
$B 5$ & 1,95 & 2,44 & 1,00 & 2,04 & 3,07 & 3,17 & 4,94 & 3,11 \\
$M W$ & 319,3 & 286,3 & 240,3 & 254,3 & 270,3 & 290,3 & 310,3 & 316,3 \\
MG-VOL & 0,197 & 0,196 & 0,022 & 0,163 & 0,221 & 0,585 & 0,726 & 0,630 \\
$S A-V O L$ & 23,51 & 24,5 & 1,48 & 18,78 & 27,24 & 86,99 & 85,27 & 72,20 \\
\hline
\end{tabular}


vo e descreve o aumento da potência através do aumento de $\sigma_{\mathrm{p}}$. Compare seu valor absoluto com os coeficientes das equações 8 e 10 . O aumento desse descritor implica, necessariamente, em que grupos elétron-retiradores sejam importantes para, provavelmente, aumentar a ionização dos grupos -NHR das acilidrazinas. Mas a pouca dependência de $\sigma_{p}$ sobre a potência revela outra informação sobre o mecanismo de ação dessas acilidrazinas. A natureza da interação da droga atuando no receptor ao nível da extensão de cargas desenvolvidas no estado de transição não leva em consideração a transmissão dos efeitos eletrônicos dos substituintes para a composição da atividade farmacológica. Este resultado corrobora o fato de que somente o parâmetro de refratividade molar (e/ou lipofílico) é necessário para descrever a atividade farmacológica, já que $\sigma_{\mathrm{p}}$ também não é significativo no modelo aditivo.

Como a equação de Hansch/Fujita permite a inclusão de outros parâmetros eletrônicos que não apenas o $\sigma_{\mathrm{p}}$ de Hammett, os seguintes também foram estudados: $\sigma^{+}, \sigma, \sigma^{0}, \sigma^{-}, \sigma_{\mathrm{I}}, \sigma_{\mathrm{R}}$ e, $\mathfrak{R}$ e $f$ de Swain Lupton, sem resultar, entretanto, em modelos significativos.

\section{S. cerevisiae: Relação Linear Atividade-Lipofilia $\left(\log 1 / \mathrm{C}_{50}=\right.$ $\left.\operatorname{alog} P_{\mathrm{TA}}+\mathrm{b}\right)$}

A equação 13 mostra os resultados obtidos quando as acilidrazinas foram estudadas frente à $S$. cerevisiae e sua dependência com log $P_{T A}$, obtido a partir do método de Taylor-Aris ${ }^{13}$.

$\log 1 / \mathrm{C}_{(50) \text { S.c }}=-1,223( \pm 0,67) \log \mathrm{P}_{\mathrm{TA}}+2,673( \pm 0,49)$

$\left(\mathrm{n}=8 ; \mathrm{r}^{2}=0,771 ; \mathrm{s}=0,141 ; \mathrm{F}=20,147 ; \mathrm{r}^{2}{ }_{\mathrm{cv}}=0,532\right)$

onde $\log P_{\mathrm{TA}}$ representa o coeficiente de partição obtido diretamente do sistema celular através do método de Taylor-Aris, e não do modelo octanol-água ${ }^{13}$.

A dependência linear de $\log P$ não constitui qualquer novidade, já que é bem sabido sobre esse comportamento e a literatura está repleta de exemplos dessa natureza. Entretanto, é bom ressaltar que o aumento linear da potência não permanece assim infinitamente com o aumento dos valores de $\log P_{T A}$, já que dependências parabólicas e bilineares também são encontradas.

É importante enfatizar que o modelo mostrado pela equação 13 constitui o primeiro exemplo que demonstra o uso do coeficiente de partição obtido diretamente em sistemas celulares. Esse modelo demonstra que a determinação de $\log P$ diretamente em sistemas celulares é viável e constitui um grande avanço na tecnologia atual.

$\mathrm{O}$ coeficiente angular da equação 13 é, virtualmente, 1 , o que estabelece uma relação homo-energética entre a potência e a partição das drogas. Esse coeficiente angular é muito diferente daquele estabelecido pela equação 8 mas também é negativo. Portanto, considerações similares podem ser estabelecidas. Um coeficiente angular próximo da unidade, mas negativo, implica que as moléculas estejam quase completamente hidratadas e/ou engalfinhadas em uma cavidade hidrofílica ou em uma fenda de biomacromoléculas hidrofílicas no ponto crítico de suas ações.

Uma explicação provável para isso pode ser encontrada no fato de que a constante lipofílica da equação 8 foi obtida do sistema octanolágua, enquanto a partição mostrada na equação 13 foi obtida do próprio sistema celular. Ou seja, a lipofilia da fase biolipídica é menor do que aquela encontrada no sistema octanol-água. Este resultado está amparado pela correlação estabelecida entre $\log P_{\mathrm{TA}}$ e $\pi$ através da equação 14. É possível também que as moléculas ou suas subunidades lipofílicas sejam mantidas na superfície da biomacromolécula.

$\log P_{\text {(TA) S.c }}=0,176( \pm 0,018) \pi-0,880( \pm 0,025)$

$\left(\mathrm{n}=8 ; \mathrm{r}^{2}=0,990 ; \mathrm{s}=0,021 ; \mathrm{F}=586,67 ; \mathrm{r}^{2}{ }_{\mathrm{cv}}=0,979\right)$
Está evidente a partir da equação 14 que a contribuição lipofílica do substituinte é suficiente para descrever o coeficiente de partição em $S$. cerevisiae, embora em pequena extensão.

\section{Relação Linear Atividade-Lipofilia Calculada}

O conceito de aditividade e constitutividade permite que os coeficientes de partição para inúmeras moléculas sejam calculados. Os $\log P_{\text {calc }}$ das hidrazidas foram correlacionados com as suas potências e a equação 15 mostra o resultado.

$\log 1 / \mathrm{C}_{(50) \text { S.c }}=-0,232( \pm 0,16) \log P_{\text {calc }}+4,272( \pm 0,53)$

$\left(\mathrm{n}=8 ; \mathrm{r}^{2}=0,674 ; \mathrm{s}=0,168 ; \mathrm{F}=12,381 ; \mathrm{r}_{\mathrm{cv}}=0,095\right)$

A equação 15 é similar às demais equações que estabelecem a dependência das potências das acilidrazinas frente à $S$. cerevisiae e a constante lipofílica, $\pi$. Entretanto, há também uma consideração de extrema relevância que se refere às magnitudes dos coeficientes angulares. Para a dependência sobre $\log P_{\mathrm{TA}}$, o coeficiente é próximo da unidade, mas inferior aos valores calculados, derivados da constante lipofílica ou mesmo do parâmetro cromatográfico (veja abaixo). Parece evidente que o sistema octanol-água como mimetizador da membrana biológica é mais lipofílico do que aquele experimentado pelo sistema celular. $\mathrm{O}$ coeficiente negativo, apenas enfatiza uma vez mais que as substâncias mais hidrofílicas é que produzem as maiores potências.

Relação Linear Atividade-Lipofilia Cromatográfica $\left(\log 1 / \mathrm{C}_{50}=\right.$ $\operatorname{alog} P_{\text {oct }}+b, \log 1 / C_{50}=a \log k+b$ e $\left.\log 1 / C_{50}=a \log k_{w}+b\right)$

O parâmetro cromatográfico pretende descrever o coeficiente de partição octanol-água e o fez, mais uma vez, adequadamente. Entretanto, tem sido postulado que esse descritor também pode, naturalmente, ser incluído na análise da QSAR $^{34}$. A equação 16 mostra a dependência das acilidrazinas em estudo frente à $S$. cerevisiae.

$\log 1 / \mathrm{C}_{(50) \text { S.c }}=-0,633( \pm 0,43) \log k_{(\mathrm{w})}+5,084( \pm 1,06)$

$\left(\mathrm{n}=8 ; \mathrm{r}^{2}=0,682 ; \mathrm{s}=0,166 ; \mathrm{F}=12,854 ; \mathrm{r}_{\mathrm{cv}}{ }=0,474\right)$

A correlação mostrada na equação 16 é apenas razoável, apesar de ser estatisticamente válida. $\mathrm{O}$ coeficiente angular também é negativo e sua magnitude é da ordem de 0,6 , um coeficiente menor do que a unidade, mas comum para sistemas celulares corroborando os resultados prévios. É interessante a sensibilidade da potência frente ao parâmetro cromatográfico. O elevado valor do intercepto indica essa sensibilidade.

Tem também sido postulado que a atividade farmacológica pode ser correlacionada com o parâmetro cromatográfico log $k$ e a equação 17 mostra a correlação da potência de acilidrazinas frente à $S$. cerevisiae sobre $\log \mathrm{k}\left(75 \% \mathrm{MeOH} / 25 \% \mathrm{H}_{2} \mathrm{O}\right)$.

$\log 1 / \mathrm{C}_{(50) \text { S.c }}=-0,534( \pm 0,35) \log \mathrm{k}_{(75 \% \mathrm{MeOH} / 25 \% \mathrm{H} 2 \mathrm{O})}+3,467( \pm 0,15)$ $\left(\mathrm{n}=8 ; \mathrm{r}^{2}=0,694 ; \mathrm{s}=0,162 ; \mathrm{F}=13,620 ; \mathrm{r}^{2}{ }_{\mathrm{cv}}=0,188\right)$

Embora seja difícil estabelecer qual é a melhor entre as equações 16 e 17, está evidente que ambas são muito similares. Considerando-se, entretanto, a capacidade preditiva, $\mathrm{r}^{2}$,v a equação 16 tem melhor significado. Portanto, parece ser real o argumento de que $\log \mathrm{k}$ também pode ser usado como parâmetro cromatográfico para a partição e consequente descrição da potência biológica.

E. coli

As equações 18 a 22 mostram os resultados obtidos para a mesma série de acilidrazinas frente à $E$. coli. Muitos dos resultados dis- 
cutidos para S. cerevisiae são válidos para $E$. coli e, portanto não serão abordados novamente.

$\log 1 / \mathrm{C}_{(50) \mathrm{Ec}}=-0,298( \pm 0,14) \mathrm{p}+3,529( \pm 0,20)$

$\left(\mathrm{n}=8 ; \mathrm{r}^{2}=0,815 ; \mathrm{s}=0,169 ; \mathrm{F}=26,635 ; \mathrm{r}_{\mathrm{cv}}^{2}=0,597\right)$

$\log 1 / \mathrm{C}_{(50) \mathrm{Ec}}=-0,374( \pm 0,13)(0,1) \mathrm{MR}+3,708( \pm 0,20)$

$\left(\mathrm{n}=8 ; \mathrm{r}^{2}=0,893 ; \mathrm{s}=0,128 ; \mathrm{F}=50,503 ; \mathrm{r}^{2}{ }_{\mathrm{cv}}=0,815\right)$

$\log 1 / \mathrm{C}_{(50) \mathrm{Ec}}=-0,176( \pm 0,13) L+3,976( \pm 0,59)$

$\left(\mathrm{n}=8 ; \mathrm{r}=0,797 ; \mathrm{s}=0,238 ; \mathrm{F}=10,461 ; \mathrm{r}_{\mathrm{cv}}^{2}=0,359\right)$

$\log 1 / \mathrm{C}_{(50) \mathrm{E} c}=-1,939( \pm 1,03) \log \mathrm{P}_{(\mathrm{TA})(\mathrm{E} . c)}+1,468( \pm 0,96)$

$\left(\mathrm{n}=8 ; \mathrm{r}^{2}=0,779 ; \mathrm{s}=0,185 ; \mathrm{F}=21,132 ; \mathrm{r}^{2}{ }_{\mathrm{cv}}=0,535\right)$

$\log 1 / \mathrm{C}_{(50) \mathrm{Ec}}=-0,900( \pm 0,50) \log k_{\mathrm{w}}+5,431( \pm 1,23)$

$\left(\mathrm{n}=8 ; \mathrm{r}^{2}=0,734 ; \mathrm{s}=0,192 ; \mathrm{F}=19,353 ; \mathrm{r}_{\mathrm{cv}}^{2}=0,626\right)$

Analisando comparativamente essas equações, o primeiro aspecto que parece de extrema relevância é que há nos estudos realizados, o encontro de uma situação reversa: ou seja, tanto para $S$. cerevisiae como para E. coli as diacilidrazinas têm um coeficiente angular negativo para $\pi, \log P$ e $M R$ e, somente $\log \mathrm{P}_{\mathrm{TA}}$ e $M R$ descrevem a QSAR com uma validação estatística mais apropriada. Veja a discussão abaixo sobre a validação cruzada.

O coeficiente negativo implica em que as acilidrazinas mais hidrofílicas e/ou menos volumosas sejam as mais tóxicas para a levedura e para a bactéria Gram-negativa.

Um dos primeiros exemplos sobre este comportamento, e possivelmente um dos mais esquecidos foi mostrado por Enders e Rohr ${ }^{35}$, em 1942, quando a QSAR ainda não havia nascido!

Esses pesquisadores mostraram que a bactéria Gram-negativa $E$. coli sobreviveria um tempo suficientemente grande em tetracloreto de carbono para que a toxidez de álcoois pudesse ser investigada e, mostraram o que se conhece como efeito hidrofóbico reversível. A equação 23 mostra este resultado.

$\log 1 / \mathrm{C}=-0,42( \pm 0,20) \log P-0,67( \pm 0,12)$

$\left(\mathrm{n}=4 ; \mathrm{r}^{2}=0,976 ; \mathrm{s}=0,054\right)$

O coeficiente negativo da equação 23 estabelece que os álcoois mais hidrofílicos são mais tóxicos para a bactéria. Os álcoois polares são empurrados para fora do $\mathrm{CCl}_{4}$ na direção da membrana bacteriana mais polar. Eles observaram ainda que os álcoois são mais tóxicos em $\mathrm{CCl}_{4}$ do que em água, mas quando Staphylococcus aureus (uma bactéria Gram-positiva) foi usada, o meio praticamente não afetou a toxidez dos álcoois.

Talvez a primeira correlação envolvendo dados sobre atividade antibacteriana tenha sido desenvolvida por Bell e Roblin ${ }^{36}$, através de uma relação parabólica entre $\mathrm{p} K_{\mathrm{a}}$ e a potência de sulfas. Posteriormente, Silipo e Vittoria ${ }^{37}$ mostraram que a inibição de $E$. coli pelas sulfas era descrita por uma relação bilinear, mostrada na equação 24.

$\log 1 / \mathrm{C}=0,97( \pm 0,10) \mathrm{p} K-1,56( \pm 0,52) \log \left(\mathrm{b} .10^{\mathrm{p} K \mathrm{a}}+1\right)+0,56( \pm 0,55)$

$\left(\mathrm{n}=87, \mathrm{r}^{2}=0,878, \mathrm{~s}=0,256 ; \mathrm{p} K_{\mathrm{a}}\right.$ ideal $\left.=6,26\right)$

A equação 24 está baseada nos dados de Bell e Roblin e Seydel e colaboradores ${ }^{38,39}$.
Uma primeira análise enfatiza que os efeitos hidrofóbicos podem não ter qualquer importância e $88 \%$ da variância em $\log 1 / C$ não contém um termo em $\log P$ ou $\pi$.

Embora haja uma dificuldade com a determinação experimental de $\log P$ (ou mais precisamente $\log D)^{18,39}$, porque boa parte dos compostos estaria ionizada em $\mathrm{pH}$ fisiológico, pode ser provável a existência de colinearidade entre $\mathrm{p} K_{\mathrm{a}}$ e $\log P$ em seus valores extremos. Ou seja, compostos ionizados terão pequenos valores de log $D .{ }^{40}$ Entretanto, separar $\mathrm{p} K_{\mathrm{a}}$ da lipofilia seria mais difícil do que sugere a equação $24^{41,42}$.

Inúmeras QSARs têm mostrado que há, pelo menos, dois tipos de coeficientes angulares para os termos $\log P$ e os exemplos mostrados a seguir servem para evidenciar muitas similaridades com os resultados obtidos, que os suportam claramente. Então, algumas limitações como o número de compostos $(\mathrm{n}=8)$ passam a não ter muita importância já que os resultados refletem uma validação lateral ou pelo menos hipoteticamente lateral do modelo encontrado.

(i) Inibição do crescimento de E. coli por $\mathrm{ArCOO}^{-43}$

$\log 1 / \mathrm{C}=0,63( \pm 0,26) \log P+3,65( \pm 0,54)$

$\left(\mathrm{n}=6 ; \mathrm{r}^{2}=0,919 ; \mathrm{s}=0,138\right)$

(ii) Inibição do crescimento de E. coli por amidinas: X$\mathrm{C}_{6} \mathrm{H}_{4} \mathrm{CH}_{2} \mathrm{NH}\left(\mathrm{NH}_{2}^{+}\right) \mathrm{NHR}^{44}$

$\operatorname{logRBR}=0,67( \pm 0,17) \log P-1,73( \pm 0,52) \log \left(\beta .10^{\log P}+1\right)+0,75$ $( \pm 0,59) \sigma_{\mathrm{X}}+( \pm 0,49)$

$\left(\mathrm{n}=20 ; \mathrm{r}^{2}=0,854 ; \mathrm{s}=0,315 ; \log P_{0}=4,59( \pm 1,4)\right)$

Os coeficientes angulares das duas equações 25 e 26 são muito similares para diferentes compostos químicos. Por isso, é bem provável que ambas as séries de compostos experimentem uma mesma biofase.

A média entre ambos os coeficientes angulares é de 0,65, mas, obviamente que não se poderia imaginar que todos os coeficientes angulares fossem próximos dessa média para as células Gram-negativas. Os dois exemplos das equações $G$ da Tabela 1 e 27 mostram que esses coeficientes podem ser bem diferentes ${ }^{45}$.

$\log 1 / \mathrm{C}=0,42( \pm 0,12)$ CLOGP $+6,39( \pm 0,33)$

( $\left.\mathrm{n}=11 ; \mathrm{r}^{2}=0,865 ; \mathrm{s}=0,249\right)$

para a inibição do crescimento de $E$. coli por alquilisotiocianatos.

No caso da QSAR mostrada pela equação G da Tabela 1 parece que todos os efeitos lipofilicos estão ausentes e apenas o efeito eletrônico parece ser importante. Entretanto, como sugere a própria equação 27, onde o efeito lipofílico é importante, a QSAR prévia pode precisar de uma melhor análise.

A inibição de $50 \%$ de células de E.coli por sulfonas ${ }^{18}$ é mostrada na equação 28 .

$\log 1 / \mathrm{C}=0,61( \pm 0,13) \mathrm{CLOGP}-1,56( \pm 0,40) \log \left(\beta \cdot 10^{\text {CLOGP }}+1\right)-$ $0,48( \pm 0,24) \sigma+4,45( \pm 0,21)$

$\left(\mathrm{n}=17, \mathrm{r}^{2}=0,912, \mathrm{~s}=0,220 ; \log \mathrm{P}_{0}\right.$ ideal $\left.=1,15\right)( \pm 0,53)$

Essa equação já apareceu no formato da equação 24, mas foi reescrita por Hansch e $\mathrm{Leo}^{46}$. O modelo bilinear mostrado na equação 28 pode ser escrito na forma da equação modificada (29) quando os substituintes $\mathrm{COO}^{-}, \mathrm{NHCH}_{2} \mathrm{COO}^{-}$e $\mathrm{CONHNH}_{2}$ são excluídos.

$\log 1 / \mathrm{C}=-0,60( \pm 0,29)$ CLOGP $-0,47( \pm 0,31) \sigma+5,34( \pm 0,60)$

$\left(n=14 ; r^{2}=0,792 ; s=0,249\right)$ 
Embora a QSAR da equação 29 não apresente uma excelente correlação, ela é estatisticamente válida e seus coeficientes estão em concordância com aqueles da equação 28 e mostram que o efeito hidrófobo não é artificial. O coeficiente de partição ideal da equação 28 é pequeno e o coeficiente angular de CLOGP na equação 29 é negativo. Parece que o significado reside no fato de as sulfonas não penetrarem na célula por difusão passiva, mas, provavelmente, através de um canal polar.

Os processos pelos quais substâncias químicas entram nas células não são entendidos claramente. Há pelo menos três caminhos que são bem aceitos: a difusão passiva através da membrana (parede celular), transporte ativo por um sistema dependente de energia, e a difusão através de canais especiais. $\mathrm{O}$ transporte passivo parece favorecido pelo aumento da lipofilia em uma série de substâncias congenéricas. $\mathrm{O}$ transporte ativo depende do sistema de transporte que reconhece certas características estruturais, através do transporte por proteínas. Células Gram-negativas contém canais construídos por uma tríade de proteínas chamadas porinas, que podem ser isoladas e reconstituídas em lipossomos para a realização de experimentos extra-celulares ${ }^{47-51}$.

Essas porinas existem em uma camada extra na estrutura da parede celular e não estão presentes em células Gram-positivas. As células Gram-negativas parecem desenvolver resistência a certos tipos de substâncias tóxicas limitando a produção de porinas ou produzindo porinas com o tamanho do canal limitado. Com exceção do tamanho, as porinas atuam de maneira não específica já que permitem que uma variedade de moléculas hidrofílicas entre para o interior da célula. O limite máximo parece ocorrer para moléculas com massa molar até $500-600^{52}$.

A superfície do canal da porina deve ser bem hidrofílica em natureza, já que Nikaido e colaboradores mostraram que a passagem através das porinas está correlacionada com o log $P$ negativo ${ }^{49,50}$. Infelizmente, entretanto, os valores de $\log P$ de muitas substâncias estudados não estão disponíveis, mas esses pesquisadores mostraram que a interação de porinas em lipossomos com açúcares e seus derivados era dependente do tamanho, medido pela massa molar das substâncias. Nenhum termo hidrófobo foi necessário para a descrição da interação. Entretanto, Yoshimura e Nikaido ${ }^{53}$ estudaram uma série de $\beta$-lactamas difundindo através de canais da porina de $E$. coli $\mathrm{K}-12$ e Hansch e $\mathrm{Leo}^{54}$ derivaram a QSAR respectiva mostrada na equação 30.

$\log k=-3,09( \pm 2,3) \log M W-0,37( \pm 0,38)$ CLOGP $+9,72( \pm 6,2)$

$\left(\mathrm{n}=9 ; \mathrm{r}^{2}=0,687 ; \mathrm{s}=0,195\right)$

Hansch e Leo sugeriram que embora a equação 30 não apresente uma correlação muito boa, ela é estatisticamente válida e estabelece que tanto o tamanho quanto a lipofilia são fatores importantes. Sugerem ainda, que essa equação tem o objetivo de motivar pesquisas que confirmem essa expectativa. Mas, em nosso entendimento, o termo CLOGP não é significativo uma vez que ele pode assumir o valor zero.

Doub e colaboradores ${ }^{55}$ estudaram o efeito de sulfonamidas sobre E. coli em camundongos e, a partir de seus dados, Hansch e Leo $^{56}$ derivaram a equação 31 .

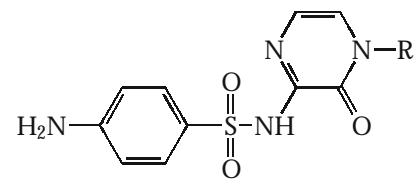

$\log 1 / \mathrm{C}=-0,79( \pm 0,18) \pi+5,74( \pm 0,33)$

$\left(\mathrm{n}=7 ; \mathrm{r}^{2}=0,962 ; \mathrm{s}=0,083\right)$
Apesar de os experimentos terem sido realizados em animais, a dependência da lipofilia é similar àquelas mostradas nas QSARs das equações 30 e 31 . Ou seja, quanto mais hidrofílica a sulfonamida mais potente o fármaco.

Os coeficientes angulares também são próximos da unidade para diferentes moléculas frente à $E$. coli .

As tetraciclinas constituem uma classe importante de antibióticos de uso clínico e vários estudos têm sido realizados para elucidar suas SARs ${ }^{57-59}$.

Um resultado interessante foi mostrado por Miller e colaboradores $^{59}$ : embora não haja qualquer correlação da potência de tetraciclinas com $\log P_{\text {app }}$, a inibição de células resistentes de $E$. coli por $\log P_{\text {app }}$ (determinado em pH 6,6) existe e está mostrada na equação 32.

A equação 32 mostra que quanto mais lipofílica for a tetraciclina, mais tóxica ela será para as células resistentes. Como as células são resistentes à tetraciclina, uma molécula polar $-\log P_{\text {app }}=-1,05$, parece que as células resistentes "ergueram" uma parede hidrófoba para sua proteção, que somente pode ser penetrada por substâncias mais lipídeo-solúveis.<smiles>CN(C)[C@H]1C(O)=C(C(N)=O)C(=O)[C@]2(O)C(O)=C3C(=O)c4c(O)cccc4C(C)(O)C3C[C@H]12</smiles>

$\log \mathrm{k}=1,30( \pm 0,52) \log \mathrm{P}_{\text {app }}-7,31( \pm 0,36)$

$\left(\mathrm{n}=12 ; \mathrm{r}^{2}=0,750 ; \mathrm{s}=0,442\right)$

Logo após sua descoberta em 1948, o cloranfenicol tornou-se um antibiótico importante. Tem sido estimado que entre os anos de 1950 e 1970 cerca de 40 milhões de pessoas usaram-no, mas devido a efeitos colaterais indesejáveis não tem sido mais usado com tanta frequência. Apesar disso, ainda há muito interesse científico nessa molécula, já que ela é capaz de inibir a síntese de proteínas por ribossomos bacterianos.

A inibição de $E$. coli por cloranfenicóis está mostrada na equação 33, onde $\mathrm{R}=\mathrm{CHCl}_{2}$.<smiles>[R]C(=O)NC(CO)C(O)c1ccc([X])cc1</smiles>

$\log k=0,93( \pm 0,27) \log \mathrm{P}-1,5( \pm 0,94) \log \left(\beta \cdot 10^{\log P}+1\right)+1,30( \pm 0,81) \sigma^{2}$ $+0,12( \pm 0,32)$

$\left(\mathrm{n}=16 ; \mathrm{r}^{2}=0,867 ; \mathrm{s}=0,280 ; \log \mathrm{P}_{0}=1,92( \pm 0,51)\right.$

$\mathrm{Na}$ equação $33, k$ representa a constante de rapidez do crescimento microbiano. $\mathrm{O}$ valor de $\log P_{0}$ é relativamente pequeno para culturas de células, sugerindo que algo mais do que a penetração celular associada ao aumento da lipofilia das moléculas pode estar participando do processo. Possivelmente, o sítio de ação tenha uma capacidade hidrofóbica limitada.

Tem sido sugerido que as células de leveduras parecem ser mais sensíveis a compostos hidrofóbicos do que bactéricas ${ }^{60}$. De qualquer maneira, parece evidente que os resultados obtidos e que consideram a atividade biológica de acilidrazinas frente à $E$. coli estão amparados em alguma evidência experimental de outras séries de compostos, validando dessa forma as QSARs propostas. 


\section{Correlação entre $\log P_{\text {bio }}$ e $\log P_{\text {oct }}$}

A existência de correlações extratermodinâmicas entre as potências das acilidrazinas e os coeficientes de partição obtidos do sistema octanol-água, do sistema cromatográfico que o mimetiza e até mesmo aquele determinado no próprio sistema celular $\left(\log P_{\mathrm{TA}}\right)$ pode ser resumida através da Figura 1. fase octanol

$$
\Downarrow \quad P_{\text {octanol }}
$$

fase aquosa biofase

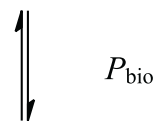

fase aquosa
Figura 1. Modelagem de $\log P$ em octanol e biofase com a fase aquosa

Um postulado semelhante ao de Hammett (Collander ${ }^{61}$ ) estabelece a correlação entre $\log P_{\text {bio }}$ e $\log P_{o c t}$, mostrada na equação 34 .

$\log P_{\text {bio }}=a \log P_{\text {oct }}+b$

Postulando-se o modelo da equação 34, obtém-se as equações 35 e 36, para S. cerevisiae.

$\log P_{\mathrm{Sc}}=0,2( \pm 0,038) \log P_{\text {calc }}-1,338( \pm 0,12)$

$\left(\mathrm{n}=8 ; \mathrm{r}^{2}=0,964 ; \mathrm{s}=0,039 ; \mathrm{F}=166,57 ; \mathrm{r}_{\mathrm{cv}}^{2}=0,899\right)$

$\log P_{\mathrm{Sc}}=0,512( \pm 0,2) \log P_{\mathrm{Kw}}-1,958( \pm 0,49)$

$\left(\mathrm{n}=8 ; \mathrm{r}^{2}=0,867 ; \mathrm{s}=0,077 ; \mathrm{F}=38,82 ; \mathrm{r}_{\mathrm{cv}}^{2}=0,711\right)$

Equações similares podem ser encontradas quando $E$. coli é usada como sistema biológico. As equações 37 e 38 mostram os resultados.

$\log P_{\mathrm{Ec}}=0,169( \pm 0,037) \log P_{\text {calc }}-1,446( \pm 0,12)$

$\left(\mathrm{n}=8 ; \mathrm{r}^{2}=0,954 ; \mathrm{s}=0,038 ; \mathrm{F}=128,49 ; \mathrm{r}_{\mathrm{cv}}^{2}=0,920\right)$

$\log P_{\mathrm{Ec}}=0,446( \pm 0,15) \log k_{\mathrm{w}}-2,000( \pm 0,36)$

$\left(\mathrm{n}=8 ; \mathrm{r}^{2}=0,904 ; \mathrm{s}=0,056 ; \mathrm{F}=56,35 ; \mathrm{r}_{\mathrm{cv}}^{2}=0,781\right)$

Todas as correlações são excelentes e podem ser consideradas como representativas do fato de que a partição na biofase é mimetizada pelo sistema octanol-água. Entretanto, não se tratam de relações tipicamente homo-energéticas.

\section{Validação Cruzada: E. coli versus $S$. cerevisiae}

O correto entendimento das relações entre estrutura química e atividade biológica depende da validação lateral da QSAR $^{1,5-10}$, ou seja, através de sua relação com uma matriz de relações autoconsistentes.

Como a atividade biológica de um composto é a combinação de vários efeitos distintos conhecidos e desconhecidos, é importante a determinação de diferentes efeitos biológicos em diferentes sistemas. A agregação desses efeitos e um "número mágico" - atividade biológica, reduz o conteúdo da informação e, portanto, faz-se mister a validação lateral.

A validação lateral realizada e agora mostrada está usando o seguinte conceito: a mesma série de compostos é estudada frente a diferentes sistemas celulares ${ }^{5}$.
A equação 39 mostra a dependência linear da potência de acilidrazinas frente à $S$. cerevisiae versus a potência frente a $E$. coli . em uma relação de validação lateral.

$\log 1 / \mathrm{C}_{50}(\mathrm{Sc})=0,489( \pm 0,16) \log 1 / \mathrm{C}_{50}(\mathrm{Ec})+2,065( \pm 0,49)$

$\left(\mathrm{n}=8, \mathrm{r}^{2}=0,904, \mathrm{~s}=0,093, \mathrm{~F}=56,44, \mathrm{r}_{\mathrm{cv}}^{2}=0,788\right)$

A equação acima representa uma relação extratermodinâmica entre atividades biológicas, ou seja, a atividade frente a leveduras e a atividade frente a bactérias, para a mesma série de compostos.

O processo de transporte é, aparentemente, o mesmo. A equação 40 estabelece uma correlação entre os coeficientes de partição em $S$. cerevisiae e E. coli.

$\log P_{\text {S.c. }}=1,147( \pm 0,25) \log P_{\text {E.c. }}+0,338( \pm 0,23)$

$\left(\mathrm{n}=8 ; \mathrm{r}^{2}=0,954 ; \mathrm{s}=0,045 ; \mathrm{F}=125,22 ; \mathrm{r}_{\mathrm{cv}}^{2}=0,921\right)$

A equação 40 indica a existência de uma relação extratermodinâmica na partição entre a mesma série de compostos em diferentes sistemas celulares. Os coeficientes da equação 40 são positivos: o coeficiente angular tende a um enquanto que o linear tende a zero. O coeficiente angular próximo da unidade revela uma relação homoenergética entre as partições e pode ser uma consequência de modos de transportes similares. Ou seja, como a propriedade lipofílica não difere para compostos correspondentes, o efeito dos substituintes no processo de transporte é similar. Portanto, o processo de transporte da mesma série de compostos através de dois sistemas celulares diferentes deve experimentar um ambiente físico-químico similar. Este resultado sugere que os compostos perturbam a membrana para produzir o resultado final da mesma maneira.

O intercepto revela que, provavelmente, no início do processo as células de $S$. cerevisiae são mais sensíveis ao efeito lipofílico dos substituintes.

\section{CONCLUSÃO}

Os resultados acima descritos aliados a aqueles obtidos da literatura sugerem que a obtenção de um modelo em QSAR não é o suficiente para descrever um sistema heterogêneo como o biológico. Muitas vezes, um sistema homogêneo definido dentro dos limites da físicoquímica orgânica é usado comparativamente a esses sistemas biológicos heterogêneos. $\mathrm{O}$ fato de sua comparação ser possível estabelece um critério mais apropriado e robusto para a validação da QSAR, principalmente quando ela for usada como modelo de predição para a atividade farmacológica de substâncias jamais sintetizadas.

Os resultados apresentados neste artigo, entretanto, constituem apenas algumas introjeções às possíveis relações de interação química-sistema biológico. Elucidar essas interações extremamente complexas não pode estar resumida a uma simples questão polinomial. Serão necessários que trabalhos cuidadosos de químicos(as) medicinais, juntamente com uma miríade de outras especialidades, sejam realizados e validados em bioquímica e/ou farmacologia antes mesmo que seus efeitos sejam delineados apropriadamente.

Dessa forma, este trabalho tem também o objetivo de incentivar a outros(as) pesquisadores(as) preocupações relativas às validações cruzadas, com características impressas de tal forma que os modelos não sejam apenas modelos, mas, muito mais do que isso, que sirvam para descrever a mãe natureza um pouco mais de perto.

\section{GLOSSÁRIO DE TERMOS}

$\log k=$ constante de rapidez ou equilíbrio de uma reação química; $\rho=$ medida da suscetibilidade de uma reação química ao efeito 
eletrônico do substituinte de Hammett; $\sigma=$ efeito eletrônico do substituinte de Hammett; QSAR, do inglês, relações quantitativas entre estrutura química e atividade farmacológica; ${ }^{3} \chi^{\mathrm{v}}=$ índice de conectividade de valência-caminho de ordem três; $\log \mathrm{P}=$ coeficiente de partição obtido, em geral, de octanol/água; $\mathrm{n}=$ número de objetos (compostos) em estudo; $r^{2}=$ coeficiente de correlação que mede a capacidade de ajuste de pontos a uma curva; $\mathrm{s}=$ desvio padrão ao ajuste da curva; $\mathrm{F}=$ teste de Fisher; $\mathrm{r}^{2}{ }_{\mathrm{cv}}=$ validação cruzada que mede a capacidade preditiva do modelo. Os valores entre parênteses nas equações representam o limite de confidência de $95 \%$; $\log 1 / \mathrm{C}_{(50)}=$ concentração necessária para inibir $50 \%$ do crescimento ou metabolismo celular; $\mathrm{MR}=$ refratividade molar; $\mathrm{L}=$ mede o comprimento do substituinte ao longo de um eixo; $\pi=$ constante lipofílica; $\log P_{\mathrm{TA}}$ = coeficiente de partição obtido pelo método de Taylor Aris; $\log P_{\text {calc }}$ = valores de $\log \mathrm{P}$ calculados por método fragmental; $\mathrm{CLOGP}=$ valores de $\log \mathrm{P}$ calculados pelo programa CLOGP; $\log \mathrm{k}=$ fator cromatográfico de capacidade; $\log \mathrm{k}_{\mathrm{w}}=$ fator cromatográfico de capacidade obtido por extrapolação para $0 \%$ do agente modificador; $\log \left(\beta .10^{\mathrm{pKa}}+1\right)=$ modelo bilinear para a resposta biológica dependente da constante de ionização e de sua fração; $\log \left(\beta \cdot 10^{\text {CLOGP }}+1\right)=$ idem, para a fração de partição; $\log \mathrm{P}_{\text {bio }}=$ coeficiente de partição obtido diretamente em um sistema biológico: Sc para S. cerevisiae e Ec para E. coli.

\section{AGRADECIMENTOS}

Os autores agradecem ao CNPq, FAPEMIG e FINEP pelo apoio financeiro aos projetos em realização no NEQUIM. Também agradecem a Oxford Molecular, Ltd., por fornecer o programa TSAR.

\section{REFERÊNCIAS}

1. Garg, R.; Gupta, S. P.; Gao, H.; Babu, M. S.; Debnath, A. K.; Hansch, C.; Chem. Rev. 1999, 99, 3525.

2. Hansch. C.; McKarns, S. C.; Smith, C. J.; Doolittle, D. J.; Chem-Biol. Interact. 2000, 127, 61 .

3. Hansch, C.; Crit. Rev. Toxicol. 1995, 25, 67.

4. Hansch, C.; Leo, A. Em Exploring QSAR. Fundamentals and Applications in Chemistry and Biology; Heller, S. R., ed.; ACS: New York, 1995.

5. Hansch, C.; Acc. Chem. Res. 1993, 26, 147.

6. Kurup, A.; Garg, R.; Corwin, C.; Chem. Rev. 2000, 100, 909.

7. Gao, H.; Denny, W. A.; Garg, R.; Hansch, C.; Chem.-Bio. Interact. 1998, 116, 157.

8. Hansch, C.; Gao. H.; Chem. Rev. 1997, 97, 2995.

9. Hansch, C.; Hoekman, D.; Gao, H.; Chem. Rev. 1996, 96, 1045.

10. Garg, R.; Denny, W. A.; Hansch, C. Bioorgan. Med. Chem. 2000, 8, 1835.

11. Montanari, M. L. C.; Tese de Doutorado, Universidade Federal de Minas Gerais, Brasil, 1998.

12. Montanari, M. L. C.; Beezer, A. E.; Montanari, C. A.; Piló-Veloso, D.; J. Med. Chem. 2000, 43, 3448.

13. Montanari, M. L. C.; Beezer, A. E.; Montanari, C. A.; Piló-Veloso, D.; Volpe, P. L. O.; Mitchell, J. C.; Quant. Struct.-Act. Relat. 1998, 17, 102.

14. TSAR, v. 3.21. Oxford Molecular, Ltd., Oxford: U.K.

15. Sybyl, v.6.5.3. Tripos, Inc.

16. Seydel, J. K.; Schaper, K. -J.; Wempe, E.; Cordes, H. P.; J. Med. Chem. 1976, 19, 483.

17. Montanari, M. L. C.; Beezer, A. E.; Montanari, C. A.; Thermochim. Acta 1999, 328, 91 .

18. Coats, E. A.; Cordes, H. -P.; Kulkarni, V. M.; Richter, M.; Schaper, K. -J.; Wiese, M. Seydel, J. K.; Quant. Struct.-Act. Relat. 1985, 4, 99.

19. Seydel, J. K.; Burger, H.; Saxena, A. K.; Coleman, M. D.; Smith, S. N.; Perris, A. D.; Quant. Struct.-Act. Relat. 1999, 18, 43.
20. Referência 4, p. 435.

21. Tsai, R. S.; Fan, W. Z.; El Tayar, N.; Carrupt, P. A.; Testa, B. Kier, L. B.; J. Am. Chem. Soc. 1993, 115, 9632 .

22. Schurhammer, R.; Wipff, G.; J. Mol. Struct.-Theochem. 2000, 500, 139.

23. Silipo, C.; Vittoria, A.; Tute, M. S. Em Comprehensive Medicinal Chemistry, The Rational Design, Mechanistic Study \& Therapeutic Applications of Chemical Compounds, Ed. Ramsden, C. A.; Quantitative Drug Design, 1990, Pergamon Press, vol. 4, p. 153.

24. Charton, M.; Charton, B. I.; J. Org. Chem. 1979, 44, 2284.

25. Dunn, W. J. III, Eur. J. Med. Chem.-Chim. Ther. 1977, 12, 109.

26. Domine, D.; Devillers, J.; Chastrette, M.; J. Med. Chem. 1994, 37, 973; Idem, ibidem, p. 981.

27. Cammarata, A.; Yau, S. J.; Rogers, K. S.; J. Med. Chem. 1971, 14, 1211.

28. Bustamante, P.; Escalera, B.; Martin, A.; Selles, E.; J. Pharm. Sci. 1989, $78,567$.

29. Agin, D.; Hersh, L.; Holtzman, D.; Proc. Natl. Acad. Sci. U.S.A. 1965, 53, 952.

30. Referência 4,p. 80

31. Abraham, M.; McGowan, J. ; J. Chromatogr. 1987, 23, 243.

32. Pearlman, R.; University of Texas, Austin: Texas.

33. Kubinyi, H. Em QSAR: Hansch Analysis and Related Approaches. Methods and Principles in Medicinal Chemistry; Mannhold, R.; Krogsgaard-Larsen, P.; Timmerman, H., eds.; VCH: Weiheim, 1993.

34. Montanari, M. L. C.; Veloso, D. P.; Cass, Q. B.; Montanari, C. A.; J. Liq. Chromatogr. Relat. Technol. 1997, 20, 1049.

35. Enders, G.; Rohr, E.; Liebigs. Ann. Chem. 1942, 552, 167.

36. Bell, P. H.; Roblin, Jr., R. O.; J. Am. Chem. Soc. 1942, 64, 2905.

37. Silipo, C.; Vittoria, A.; Farmaco 1979, 34, 858.

38. Seydel, J. K.; J. Med. Chem. 1971, 14, 724; Hansch, C.; Classical and Three-Dimensional Qsar in Agrochemistry 1995, 606, 254.

39. Miller, G. H.; Doukas, P. H.; Seydel, J. K.; J. Med. Chem. 1972, 15, 700.

40. Britto, M. M.; Cass, Q. B.; Montanari, C. A.; Aboul-Enein, H. Y.; Chromatographia 1999, 22, 2139.

41. Martin, Y. C.; Hackbarth, J. J.; J. Med. Chem. 1976, 19, 1033.

42. Balaz, S.; Perspect. Drug Discovery Des. 2000, 19, 157.

43. Baldinger, L. H.; Nieuwland, J. A.; J. Am. Pharm. Assoc. 1933, $22,711$.

44. McKay; A. F.; Garamaise, D. L.; Baker, H. A.; Hawkins, R. L.; Falta, B.; Gaudry, R.; Paris, G. Y.; J. Med. Chem. 1963, 6, 587.

45. Vlachova, D.; Drobnica, L.; Collect. Czech. Chem. Commun. 1966, 31, 997. 46. Referência 4, p. 432.

47. Nikaido, H.; Vaara, M.; Microbiol. Rev. 1985, 49, 1.

48. Nikaido, H.; Rosenberg, E. Y.; Foulds, J.; J. Bacteriol. 1983, 153, 232.

49. Fajardo, D. A.; Cheung, J.; Ito, C.; Sugawara, E.; Nikaido, H.; Misra, R.; J. Bacteriol. 1998, 180, 4452.

50. Harder, K. J.; Nikaido, H.; Matsuhashi, M.; Antimicrob. Agents Chemother. 1981, 20, 549 .

51. Nikaido, H.; Rosenberg, E. J.; J. Bacteriol. 1983, 153, 241.

52. Lipinski, C. A.; Lombardo, F.; Dominy, B. W.; Feeney, P. J.; Adv. Drug Del. Rev. 1997, 23, 3; Montanari, C. A.; Bolzani, V. S.; Quim. Nova, no prelo.

53. Yoshimura, F.; Nikaido, H.; Antimicrob. Agents Chemother. 1985, 27, 84; Simonet, V.; Mallea, M.; Pages, J. M.; Antimicrob. Agents Chemother. 2000, 44, 311 .

54. Referência 4, p. 429.

55. Doub, L.; Krolls, U.; Vandelbelt, J. M. e Fischer, M. W.; J. Med. Chem. 1970, 13, 242

56. Referência 4, p. 434.

57. Hansch, C. Em Drug Design; Ariëns, E. J., ed.; Academic: New York, 1971, vol. 1 , p. 271

58. Peradejordi, E.; Martin, A. N.; Cammarata, A.; J. Pharm. Sci. 1971, 60, 576.

59. Miller, G. H.; Smith, H. L.; Rock, W. L.; Hedberg, S.; J. Pharm. Sci. 1977, $66,88$.

60. Hansch, C.; Kim, D.; Leo, A. J.; Novellino, E.; Silipo, C.; Vittoria, A.; CRC Crit. Rev. Toxicol. 1989, 19, 185.

61. Collander, R.; Physiol. Plantarum 1960, 13, 179; Montanari, M. L. C.; Montanari, C. A.; Pilo-Veloso, D.; Cass, Q. B.; J. Liq. Chromatogr. Rel. Technol. 1997, 20, 2495. 